Interested parties are invited to submit proposals or views to the working party, and are asked to send them to the secretary, Joint Working Party on Sixth Form Curriculum, the Schools Council, 160 Great Portland Street, London WI.

\section{Better Materials}

The Explosives Research and Development Establishment (ERDE) of the Ministry of Technology-at Waltham Abbey, Essex, last week held its first open days since it was established in 1945. One of the aims of the open days seems to have been to acquaint industry with the work in progress at ERDE on the development of polymers and the design of high strength composite materials. The 500 acre site at Waltham Abbey has a long association with explosives going back more than four conturies, first as a private gunpowder works and later as the Royal Gunpowder Factory. It has a network of canals which at one time used to be the means of transport within the site. The facilities at ERDE include remote handling equipment for the testing of now explosives and the

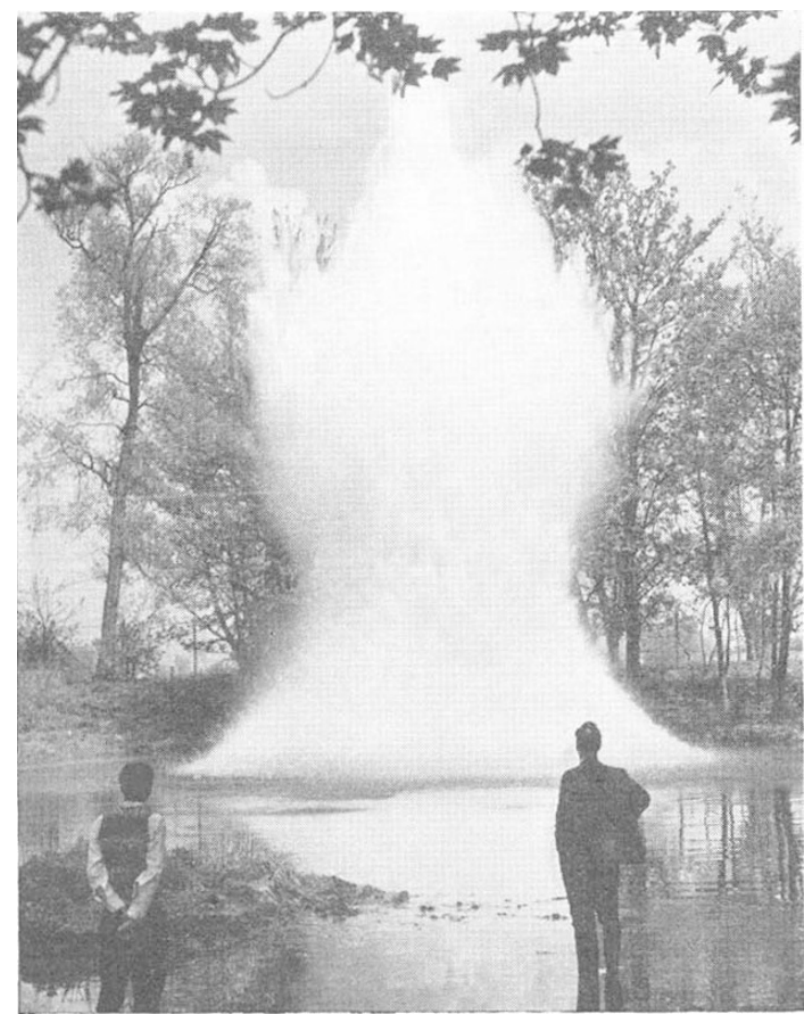

Testing underwater explosives at the Explosives Research and Development Establishment.

large-scale processing of rocket propellants. Although explosives and propellants still form the mainstay of the work at Waltham Abbey, about 30 per cent of the establishment's effort is now devoted to materials research. ERDE seems to have become particularly adept at developing materials of high strength by adding reinforcing fibres. Some of the new composite materials have properties which may make them suitable for applications in the aviation industry.

One of the lines of research under way is the investigation of thermoplastics containing various fibrous fillers as alternatives to glass-fibre. A number of fibres have been tried, including asbestos, carbon and whiskers of silicon carbide, in a range of thermoplastics. Asbestos and silicon carbide fibres have been particularly successful-silicon carbide giving the better properties but at a higher cost than asbestos.

Work on the strengthening of thermoplastics is leading on to the improvement of the properties of metals by the addition of reinforcing fibres. The addition of whiskers of silicon carbide to aluminium is producing the strength and high temperature properties of titanium at only half the weight. So far, reinforced aluminium has only been produced on a pilot plant basis, but it looks as if the chief difficulties -the manufacture of whiskers of silicon carbide and their alignment in the metal-have in principle at least been overcome. Now that the aviation industry is beginning to need the properties of titanium in the construction of supersonic aircraft, the prospects of aluminium reinforced by fibres look attractive. It is materials such as these which are likely to make weight problems such as those the American supersonic transport is facing at present a less important factor in the design of future generations of aircraft.

Apart from this work on composites, the materials sections at ERDE are also working on the improvement of polymers for applications such as flexible fuel tanks, dracones, arrester tapes for aircraft and hovercraft skirts. Here the problems are the degradation of the material by the effects of heat, light and fucls. By investigating the way in which the polymers break down under these influences, ways of modifying the polymers to make them more permanent are being developed.

\section{Analysis of MEDLARS}

A FULL-SCALE evaluation of the performance of MEDLARS (Medical Literature Analysis and Retrieval System) by the National Library of Medicine in the United States shows that the system is operating on average at about 58 per cent recall and 50 per cent precision, that is to say, it retrieves 58 per cent of relevant documents in response to a specific request, at the expense of having 50 per cent irrelevant documents retrieved at the same time. The results of the analysis, the first large-scale evaluation of a major operating information system, have recently been published in a report from the library (Evaluation of the MEDLARS Demand Search Service, US Dept of Health, Education and Welfare, 1968). Unfortunately the report is written in such a way that for a nonspecialist in information retrieval systems it is difficult to tell the wood from the trees. This is a pity, because the user of the service ought to be as aware of the results as the MEDLARS specialist, and indeed one of the rather cryptically written recommendations is that there is a great need for improvement in MEDILARS "at the interface between user and system".

The test programme was conducted impartially by a specially recruited "information systems evaluator", with the help of an advisory committee appointed by the director of the National Library of Medicine. An analysis was made of 300 actual requests made to the system in 1966 and 1967. It concentrated on the evaluation of the demand search function of MED. LARS, that is, the behaviour of retrospective literature 
searches in response to specific demands. The collection of material on which the searches were made consisted of more than half a million citations to journal articles in the biomedical field, input to the January 1964 and subsequent issues of the monthly Index Medicus. This collection is growing at the approximate rate of 200,000 citations per year. Articles from about 2,400 scientific journals are indexed at an average level of $6 \cdot 7$ terms per item using a controlled vocabulary of Medical Subject Headings (MeSH). Over three thousand demand searches are processed annually at the National Library of Medicine, additional searches being handled at regional MEDLARS centres in the United States, in the United Kingdom and in Sweden. 'The present study was confined to the United States. A demand search is conducted by a serial search of the index term profiles of the 700,000 citations on magnetic tape. This search is essentially a matching process; the index term profiles of journal articles are matched against a search formulation, which is a translation of a subject request into the controlled vocabulary of the system.

The principal objectives of the test programme included a study of the demand search requirements of the users: the determination of how effective and efficient the present service is in meeting these requirements: and how the requirements of users could be met in the future.

The results showed that on average the system retrieves about 65 per cent of the "major value" literature from its collection of data. Few of the individual search results, however, were in the area bounded by the average ratios \pm 5 per cent. In fact, the results were widely scattered. Some of the searches appear to have performed well with high recall accompanied by high precision. Other searches had very unsatisfactory recall results. It seems that a rather different average result was expected. The report states that the system was expected to function in a high recall, low precision way, in the region of, for example, $75-90$ per cent recall at $10-20$ per cent precision. It is suggested that the reason why on average MEDLARS is operating at 58 per cent recall and 50 per cent precision may be because the searchers, unconsciously or consciously, choose to operate in this general area. MEDLARS is now retrieving an average of 175 citations per search; to operate at an average recall of 85-90 per cent, and an average ratio around 20-25 per cent, would mean that MEDLARS would need to retrieve in each search an average of 500-600 citations. which many users would not be willing to scan. Little is in fact known about the recall and precision requirements and tolerances of MEDLARS users. The report suggests, however, that a decision on this subject ought not to be fixed. Each user has his requirements and the MEDLARS demand search request form ought to be redesigned to cater for recall requirements and precision tolerances of each user.

\section{How Did Mycenae Fall?}

A sURVEY of available palaeoclimatological evidence by $\operatorname{Dr} H$. E. Wright, director of the Limnological Research Center of the University of Minnesota, seems to cast doubt on the suggestion that the fall of Mycenae was brought about by a climatic change. This idea was put forward by Professor Rhys Carpenter in a book called Discontinuity in Greek Civilization (Cambridge, 1966 ) in which he suggested that the extension of the summer droughts into autumn and spring caused repeated failure of crops in southern Greece and thus the breakdown of the Mycenaean economy. Professor Rhys Carpenter suggested that this resulted in the abrupt fall of the civilization-in about $1200-1000 \mathrm{BC}$ -an event which has never been adequately explained.

In the current issue of Antiquity (XLII, 123: 1968) Dr Wright reviews the evidence for this hypothesis which is available from pollen remains found in layers of soil dating from the time of the fall of Mycenae. He has found no indication of any vegetational change? that could have accompanied a climatic change in the Mediterranean region during Mycenaean times. Analysis of pollen from soil layers on the southern Dalmatian coast, 250 miles north of Greece, has shown that the Mediterranean evergreen oak has dominated the landscape since $4300 \mathrm{BC}$ with no sign of a climatic change. In north-western Turkey, although a reduction in the forests of beech and fir at about $2000 \mathrm{BC}$ may reflect a change to a drier climate at that time, there was no significant change around $1200 \mathrm{BC}$.

In Peloponnesus, pollen from the Osmanaga lagoon near Pylos has shown that there was an increase in the growth of olive trees to about 40 per cent of the total vegetation at about $1000-600 \mathrm{BC}$. These must have been cultivated, for wild olives now form a very small part of the Mediterranean vegetation. This seems to indicate that olive-growing characterized the postMycenaean period--known as the Greek dark ages-from 1100 to $800 \mathrm{BC}$. Dr Wright suggests that at that time olives were the chief subsistence crop, whereas the Mycenaeans had a more diversified range of crops. which have left a poor pollen record. At any rate, the flourishing olives are evidence against a climatic deterioration, and Dr Wright is forced to the conclusion that there is no reliable scientific evidence to support the theory that climatic change brought about the downfall of the Mycenaean civilization.

\section{Porton Revealed}

THE recent furore in Parliament and the press over the secrecy of the biological warfare work carried out at the Microbiological Research Establishment at Porton has led to a concession, albeit a slight one, from the Government; beginning in late 1968 or early 1969. Porton will hold an open day for the first time. The Ministry of Defence announced this in the House of Commons on June 12. Mr John Morris, Minister of Defence for Equipment, made the announcement and added that "the scientists at Porton have been subjected to quite intemperate attacks recently. . . . I. hope the open days... will relieve any public anxiety which may exist".

In answer to questions about the animals used at Porton, Mr Morris stated that all animals were well taken care of, but he believed that they could not be shown on television because of an 1876 Act of Parliament restricting photographs of animals. 'The' animals used in experiments certainly seem to be those normally found in biological laboratories-26,882 mice, 720 guinea-pigs, 825 hamsters, 60 voles, 63 monkeys and 44 sheep last year-and since 80 per cent of the work of the laboratory is unclassified, it would seem unlikely that the RSPCA would have cause for com- 